\title{
Surgical Strategies for Thoracic Myelopathy due to Ossification of Ligamentum Flavum: A Technical Note Based on Radiological Type
}

\author{
Ting WANG, Chunyan DU, Xiujun ZHENG, Yuanliang SUN, Xiangyun LIU, Jianqiang KOU \\ Affiliated Hospital of Qingdao University, Department of Spinal Surgery, Qingdao, China
}

\section{ABSTRACT}

\begin{abstract}
AIM: Ossification of the ligamentum flavum (OLF) is a primary cause of thoracic myelopathy. A relatively safe surgical technique based on radiological type is described for OLF-induced thoracic myelopathy.

MATERIAL and METHODS: Forty patients with thoracic myelopathy caused by OLF were studied retrospectively. The OLF was divided into fused and non-fused types according to the computed tomography and magnetic resonance imaging findings. All patients underwent posterior decompression. For the fused type, open-door laminectomy and for the non-fused type, French-door laminectomy surgical techniques were adopted. Preoperative, postoperative, and follow-up neurological conditions were evaluated using the modified Japanese Orthopaedic Association (mJOA) score.

RESULTS: The mean duration of symptoms was $9.2 \pm 11.5$ and $8.4 \pm 9.7$ months in the non-fused and fused groups, respectively. The apex of OLF at the most severely compressed level was located at $2.7 \pm 1.9 \mathrm{~mm}$ above the disc level: $2.4 \pm 1.6 \mathrm{and} 3.0 \pm 2.2 \mathrm{~mm}$ in the non-fused and fused groups, respectively. The preoperative mJOA scores were $5.0 \pm 1.1$ and $4.2 \pm 0.9$ in the non-fused and fused groups, respectively. After the operation, the neurological deficits were improved in all patients. With an average follow-up of 33.9 months, the mJOA score was ultimately improved in both groups.
\end{abstract}

CONCLUSION: In OLF-induced thoracic myelopathy, the en-bloc elevation of the laminae with the OLF plaque is emphasized at the key site for surgical decompression. Based on the present classification of OLF, different surgical strategies should be adopted for a safe neurological decompression.

KEYWORDS: Decompression, Laminectomy, Ossification of ligamentum flavum, Thoracic myelopathy, Thoracic spine

\section{INTRODUCTION}

$\mathrm{O}$ ssification of the ligamentum flavum (OLF) is a wellknown cause of thoracic myelopathy in East Asian countries (1). It is a slowly progressive disease that is usually discovered when the patients have advanced symptoms due to severe spinal cord compression. Surgical treatment is indicated once the thoracic OLF becomes symptomatic as conservative treatment is typically ineffective (26).
Thoracic OLF can be classified as follows: in the sagittal plane, it can be classified into round and beak types (9), and in the axial plane, into lateral, extended, enlarged, fused, and nodular types (17). Most classifications of thoracic OLF are based on its morphological appearance on computed tomography (CT) scan. When thoracic myelopathy due to OLF occurs, the compression of the spinal cord can be adequately illustrated on sagittal magnetic resonance imaging (MRI). Thus, a classification based on both CT and MRI might be beneficial for the surgical treatment. 
However, safe neurological decompression of thoracic myelopathy caused by OLF is yet challenging. The OLF compress the spinal cord tightly, thereby rendering the surgical decompression risky. In severe cases, the ossification of the dura mater with the OLF makes surgery more difficult. Hence, several surgical decompression procedures including en-bloc laminectomy $(8,21)$, laminoplasty (19), and foraminotomy (15) have been recommended. The outcomes of te surgical treatment are not always satisfactory, and the possibility of neurological deterioration remains a major concern.

In this technique-based note, we reported relatively safe surgical strategies for thoracic myelopathy caused by OLF based on the radiological type.

\section{MATERIAL and METHODS}

This study was approved by the institutional review board of our hospital. Between January 2009 and January 2015, 40 patients with thoracic myelopathy caused by OLF underwent surgical treatment consecutively, at our institution, utilizing the surgical techniques described in the present study. The indications for surgical treatment were progressive neurological impairment and severe myelopathy. Only patients who needed one-segment thoracic OLF decompression were included in the study. Patients identified as having additional clinical manifestations, such as ossification of the thoracic posterior longitudinal ligament and thoracic disc herniation, were excluded from the study.

\section{Classification of OLF}

$\mathrm{CT}$ and $\mathrm{MRI}$ were performed in all patients at the preoperative evaluation for the classification of OLF, which was divided into two types according to the findings on CT and MRI scans: the fused type and the non-fused type. For the fused type, the ossification of bilateral ligamentum flavum fused at the midline, and no epidural fat was observed on MRI at the most severe narrowing compressed level (Figures 1, 2). For the nonfused type, the ossification of bilateral ligamentum flavum did not fuse at the midline as apparent on CT, and epidural fat was recorded by MRI at the most severe narrowing level (Figures 3, 4). In definition, the level where the spinal cord was deformed morphologically by the OLF, as visible on sagittal MRI, is the most severe narrowing level. The level where only the dura was compressed by the OLF but with no spinal cord deformation did not belong to the most severe narrowing level. The vertical distance of the apex of OLF at the most severe narrowing level to the disc was measured on the sagittal T2 image of MRI (Figure 5).

\section{Surgical Techniques}

Patients were placed in the prone position with the abdomen suspended, under general anesthesia. A straight longitudinal incision was performed at the level of the diseased segment. The holes for thoracic pedicle screws were commissioned utilizing the free-hand method at the involved segment. The $\mathrm{K}$-wire was inserted in the pedicle. Intraoperative radiography was used to confirm the involved segment and the position of the K-wire in the pedicle. Before decompression, methyl

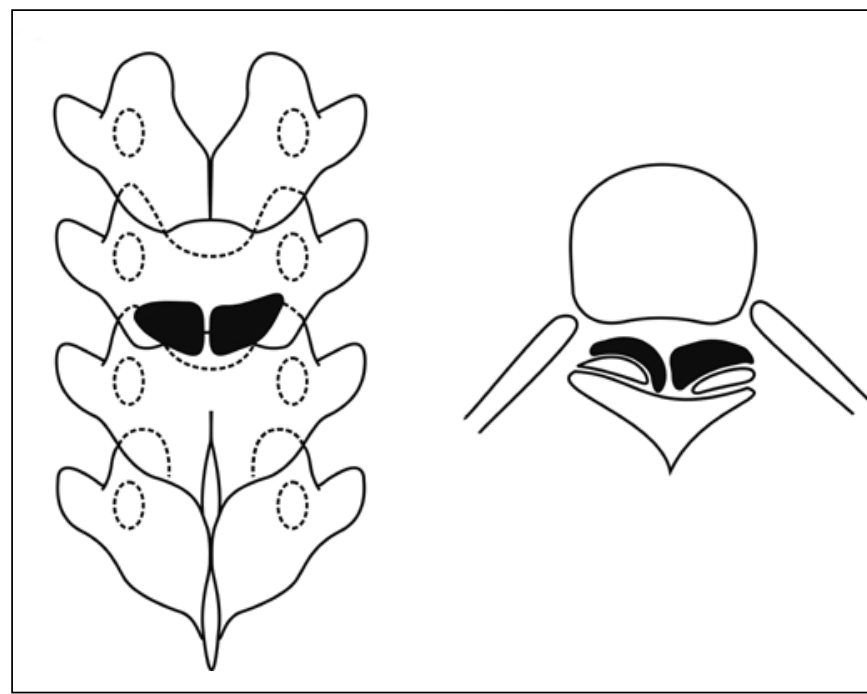

Figure 1: For the non-fused type, the ossification of bilateral ligamentum flavum does not fuse at the midline.

prednisolone (1000 mg) was infused intravenously to prevent the development of edema and secondary injury to the spinal cord.

After removing the spinous process, the outer cortex and the cancellous layer of the two laminae containing the OLF were removed by drilling, leaving the inner cortex intact. The two transverse grooves, approximately 3-4 $\mathrm{mm}$ in width, were completed at the pedicle level with a high-speed burr, thereby exposing the epidural space. Since the ligamentum flavum does not exist at the pedicle level, the OLF never develops, and the epidural space is expansive. The lateral edges of the two transverse grooves should reach the medial edge of the pedicle. Subsequently, Penfield could be used to confirm the medial edge of the pedicle.

For the fused type, two lateral longitudinal grooves, approximately $3 \mathrm{~mm}$ in width, were drilled in order to connect the lateral edge of the two transverse grooves (Figure 6). The medial edge of the longitudinal groove was required along the medial edge of the pedicle to ensure that the longitudinal grooves were outside the thoracic canal. The longitudinal grooves were deepened bilaterally to paper-like thinness. One $\mathrm{mm}$ Kerrison rongeur could be used to open one of the longitudinal grooves while the longitudinal groove on the other side remained intact as a hinge. A fine-tipped hook was utilized to gently lift the laminae with the OLF plaque en-bloc similar to that in opendoor laminoplasty. If there was any resistance, the thinness of the longitudinal groove on the hinge side would be needed. When the laminae with the OLF plaque was lifted dorsally and removed, the spinal cord was decompressed.

For the non-fused type, a surgical procedure, such as Frenchdoor, was performed (Figure 7). The laminae at the midline were opened by drilling. Since the preoperative MRI revealed epidural fat between the middle of bilateral non-fused OLF, it was safe to open it with the drill. Then, the two bilateral longitudinal grooves were made similar to the surgery in the fused type. When the bilateral longitudinal grooves were 

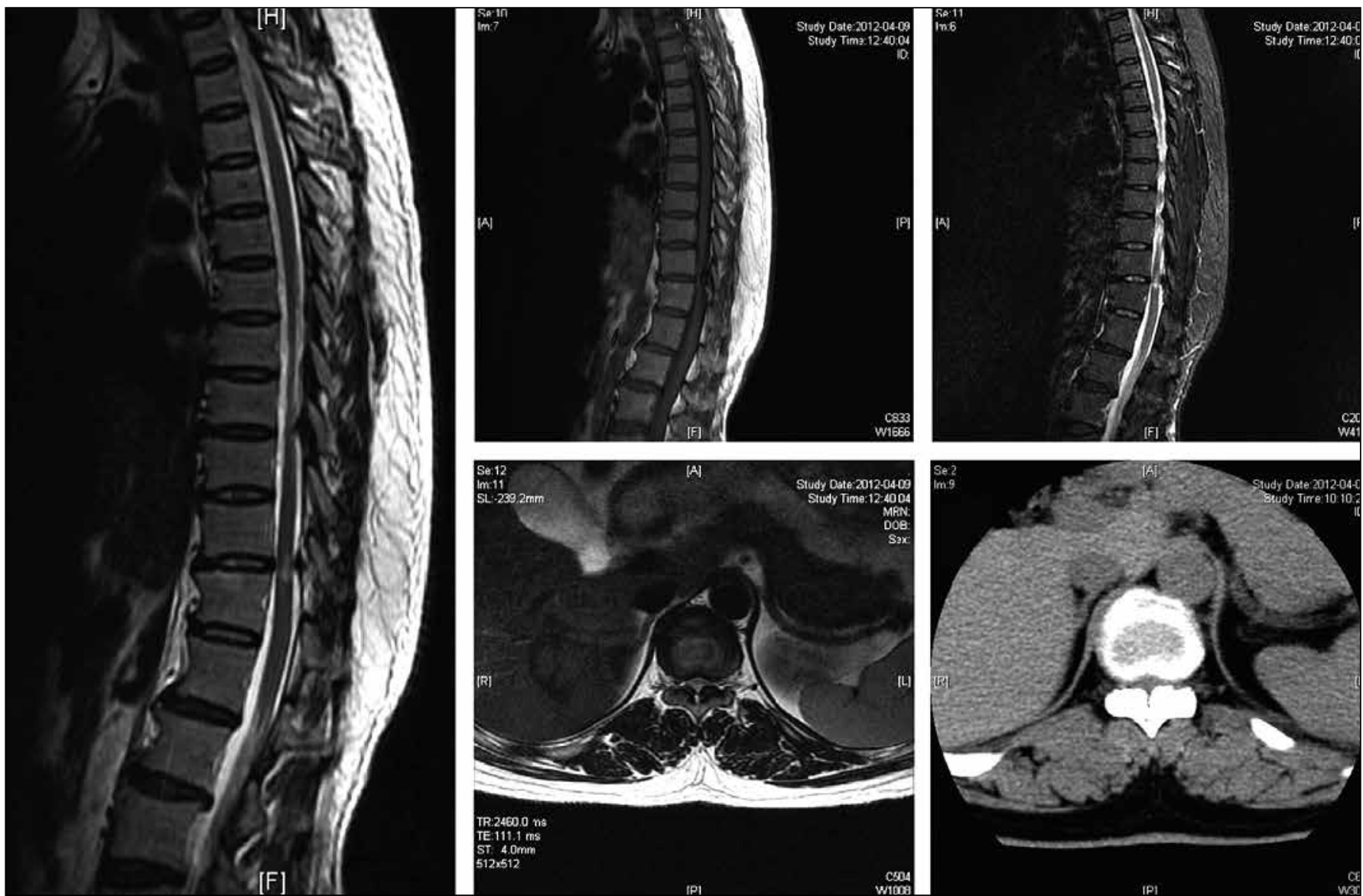

Figure 2: In the non-fused type, the bilateral ossification of ligamentum flavum does not fuse at the midline on CT, and there is epidural fat on MRI at the most severe narrowing level.

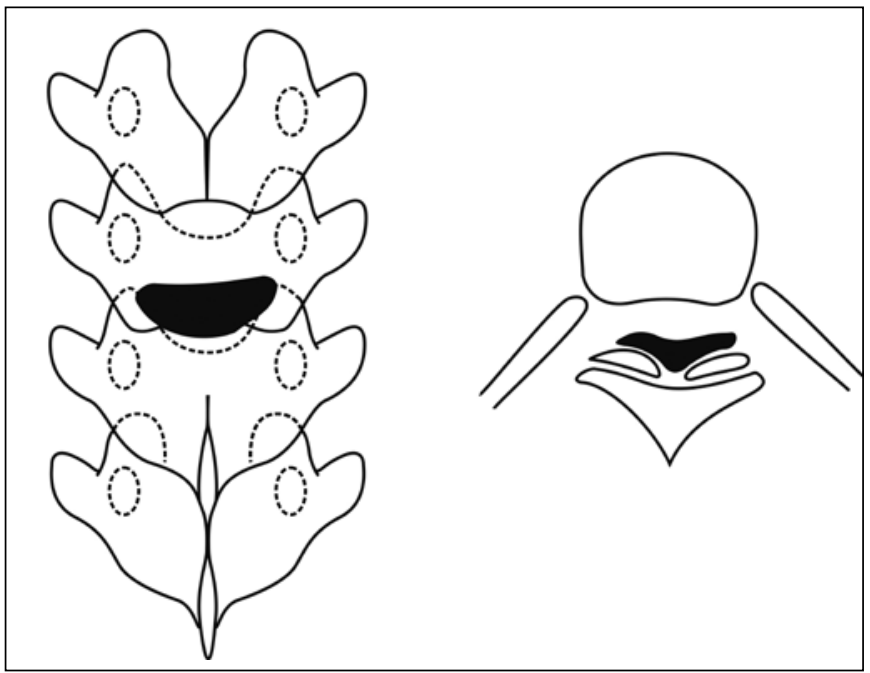

Figure 3: For the fused type, the ossification of bilateral ligamentum flavum fuses at the midline.

deepened to paper-like thinness, the hemilaminae with the OLF on both sides were opened outward and removed.

Adhesive or ossified dura mater was encountered commonly with the OLF. The OLF usually firmly adhered to the dura with no discernable plane between the OLF and dura. After enbloc elevation of the laminae with the OLF plaque, a blade was used to incise along the edge of the ossified mass. In case of dural ossification, the arachnoid membrane was maintained intact, and the dural defect was not repaired. After complete decompression and careful hemostasis, posterior fixation with the pedicle screw and posterolateral fusion with the resected laminae was performed. Subsequently, we ensured the closure of the paraspinal muscles, deep fascia, and skin meticulously. The subfascial drain was always placed. The wound drain was removed 24-48 hours after the operation. In case of a cerebrospinal fluid (CSF) fistula, bed rest was required for the patients for 2 weeks after surgery.

\section{Outcome Evaluation}

In all patients, the neurological assessment was conducted using the modified Japanese Orthopaedic Association (mJOA) scores. A maximum score of 11 indicated normal function. The neurological status was determined before and after surgery, as well as at the final follow-up. The postoperative neurological recovery was estimated on the basis of the recovery rate (RR).

$\mathrm{RR}=($ postoperative $\mathrm{mJOA}$-preoperative $\mathrm{mJOA}) /(11$ preoperative $\mathrm{mJOA}) \times 100 \%$. 

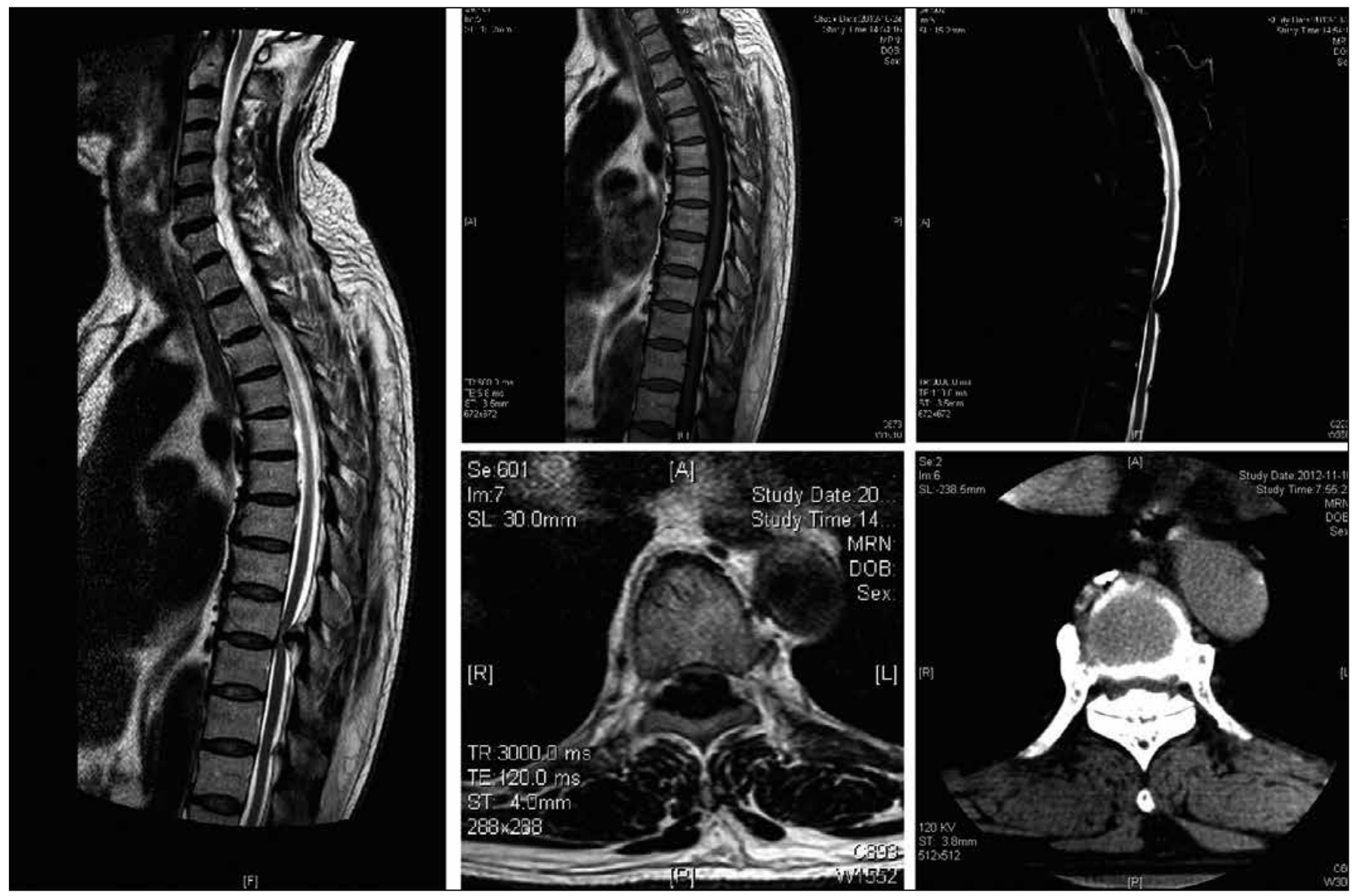

Figure 4: In the fused type, the ossification of bilateral ligamentum flavum fuses at the midline, and there is no epidural fat on MRI at the most severe narrowing compressed level.

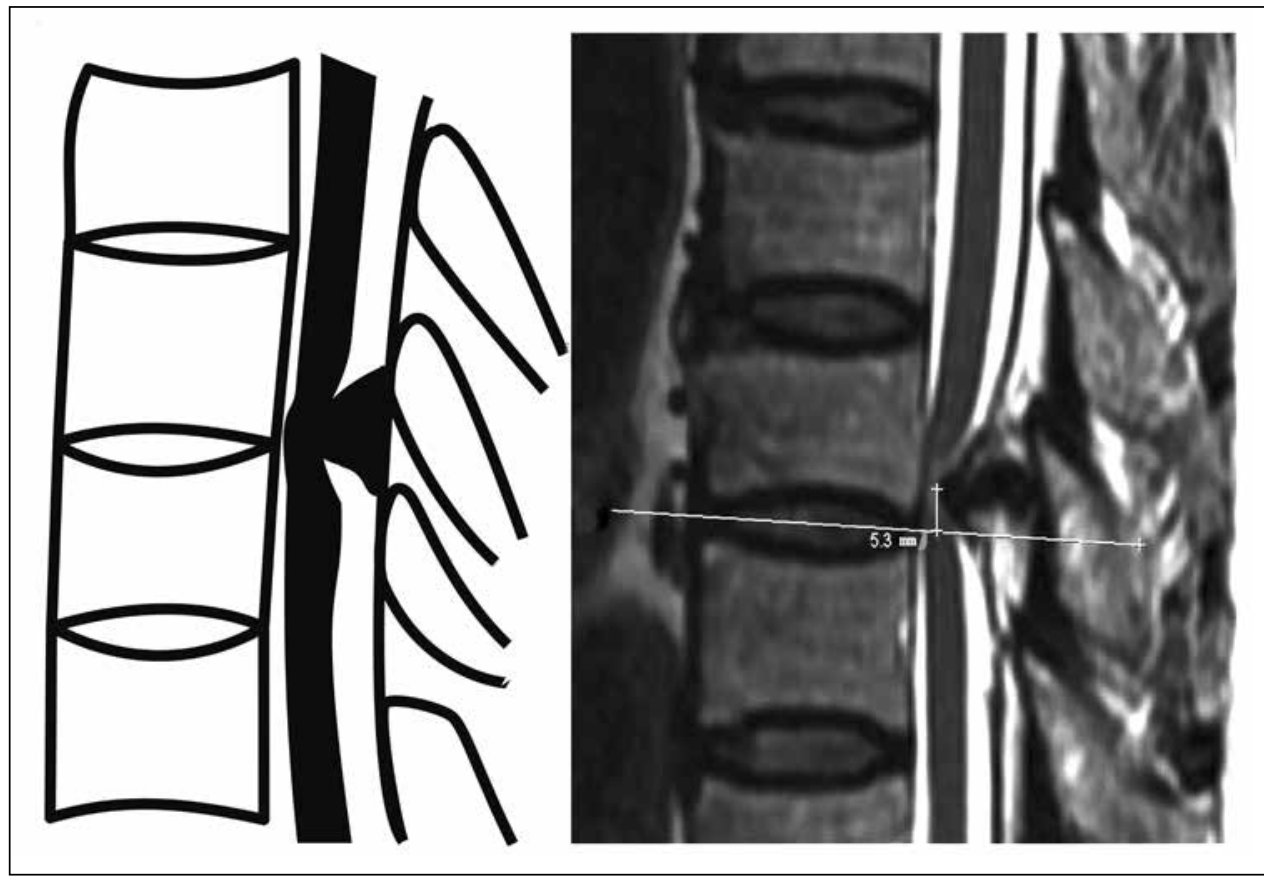

Figure 5: The vertical distance of the apex of OLF to the disc level is measured on the sagittal T2 image of MRI. 

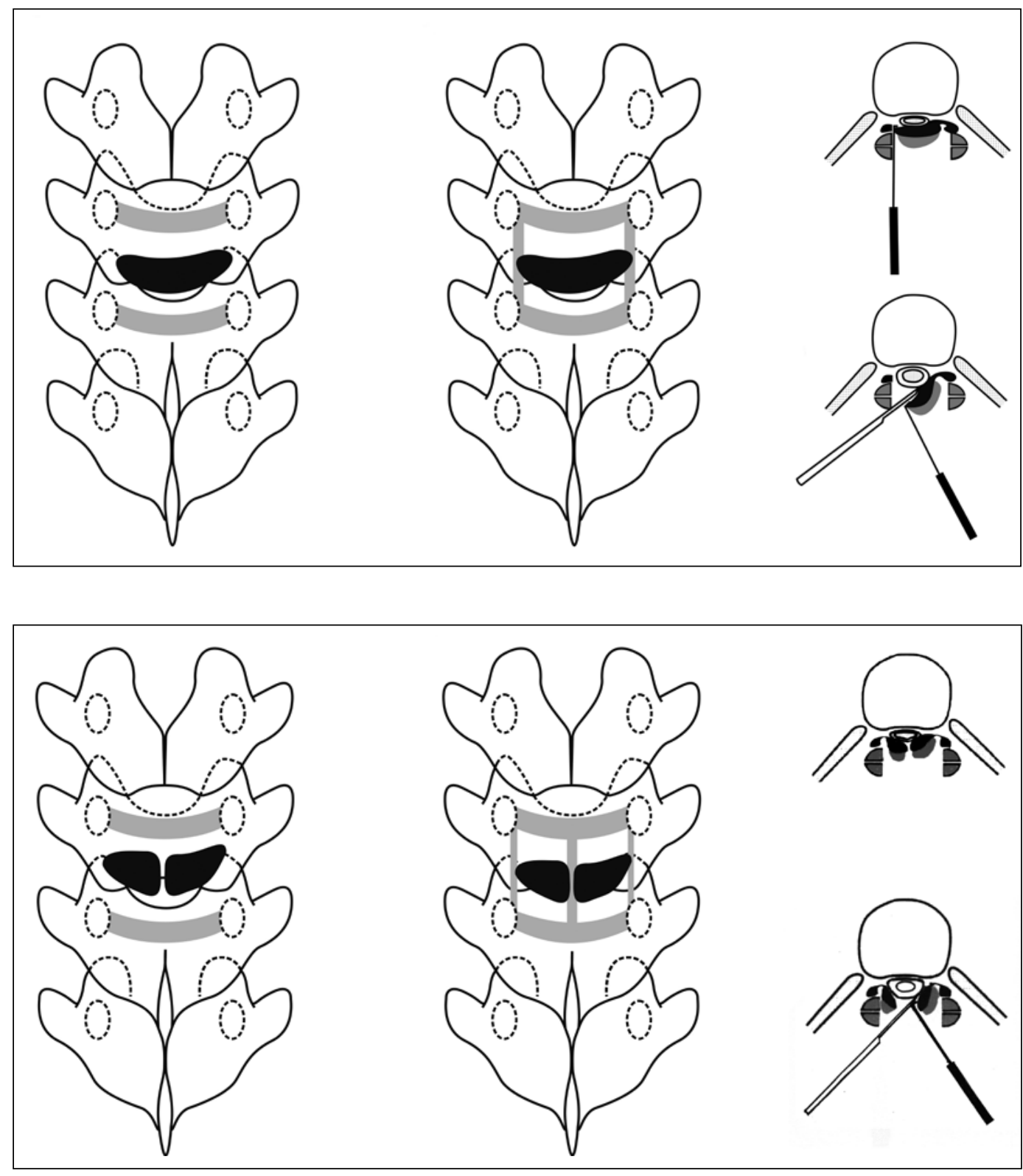

Figure 6: Two transverse grooves, about 3-4 mm wide, are made at the pedicle level with high-speed burr, and the epidural space is exposed. For the fused type, two lateral longitudinal grooves about $3 \mathrm{~mm}$ wide are then made with the drill to connect the lateral edge of the two transverse grooves. A fine-tipped hook is used to gently lift the laminae with the OLF plaque en-bloc as in open-door laminoplasty. After the en-bloc elevation of the laminae with the OLF plaque, a blade is used to incise along the edge of the ossified mass.

Figure 7: For the non-fused type, a surgical procedure, such as French-door, is performed. The laminae at the midline are opened with the drill. Then, two bilateral longitudinal grooves are made similar to the surgery in the fused type. When the bilateral longitudinal grooves are deepened to be paper-thin, the hemilaminae with the OLF on both sides are opened outward and removed.

\section{Statistical Analysis}

Results were presented as the mean \pm standard deviation. Statistical differences between the non-fused and fused groups were determined by the t-test. $p$-values $<0.05$ were considered statistically significant. Statistical analyses were performed using the SPSS 19.0 software (SPSS Inc., Chicago, IL, USA).

\section{RESULTS}

\section{Clinical Outcomes}

The study comprised 20 patients (10 males and 10 females) in the non-fused group with a mean age of 57.8 (43-75) years (Table I) and 20 patients ( 8 males and 12 females) in the fused group with a mean age of $59.1(46-74)$ years (Table
II). The mean duration of symptoms was $9.2 \pm 11.5$ months in the non-fused group and $8.4 \pm 9.7$ months in the fused group. No significant differences were observed in the duration of symptoms between the two groups $(t=0.257, p=0.800)$.

\section{Radiological Outcomes}

Fifteen segments in the non-fused group (75\%) and 19 in the fused group (95\%) were located in the lower thoracic spine (T9-12). The most commonly affected segment was the T1011 level of the vertebral body in both groups. The apex of OLF at the most severely compressed level was located at $2.7 \pm 1.9 \mathrm{~mm}$ above the disc level and this value was found to be $2.4 \pm 1.6 \mathrm{~mm}$ in the non-fused group and $3.0 \pm 2.2 \mathrm{~mm}$ in the fused group. No significant differences were noted between the two groups $(t=-0.937, p=0.360)$. 


\section{Surgical Outcomes}

The preoperative mJOA score was $5.0 \pm 1.1$ in the non-fused group and $4.2 \pm 0.9$ in the fused group $(t=1.891, p=0.074)$. After the operation, the neurological deficits in all the patients were improved and neurological deterioration did not occur. The mJOA score significantly improved to $7.7 \pm 1.0$ in the non-fused group and $7.3 \pm 1.0$ in the fused group $(t=0.984, p=0.338)$. With an average follow-up of 33.9 (25-48) months, the mJOA score ultimately improved to $8.9 \pm 1.0$ in the non-fused group and $8.9 \pm 0.8$ in the fused group $(t=0.160, p=0.874)$. The recovery rate was $66.5 \pm 12.9 \%$ in the non-fused group and $69.0 \pm 9.2 \%$ in the fused group. No significant differences were observed in the recovery rate between the two groups $(t=-0.705, p=0.489)$.

During the operation, dural ossification was found in 6 patients $(30 \%)$ in the non-fused group and 11 patients (55\%) in the fused group. A complete resection of the ossified segment was performed in all patients. CSF leakage was detected in 1 patient in the non-fused group and 4 patients in the fused group. Two patients with CSF leakage in the fused group exhibited wound dehiscence at the postoperative first week and recovered after wound debridement.

\section{DISCUSSION}

The ligamentum flavum is comprised of two parts: the interlaminar portion medially and the capsular portion laterally (20). Ossification typically begins to develop in the capsular portion and extends gradually to the interlaminar area, followed by ventral enlargement, compressing the spinal cord. In some cases, the bilateral ossification may fuse in the middle of the lamina. The majority of the thoracic OLF classifications are based on the morphological appearance in the sagittal or axial planes. In the sagittal plane, OLF was classified into the round and beak types by Kuh et al.(9). In the axial plane, the Sato classification is most commonly used (17), and classifies the OLF morphology in cross-sectional CT images into one of the following five types: lateral, extended, enlarged, fused, or nodular. The categorization of OLF based on the non-fused and fused types was originally proposed by Kuh et al. (9).

Table I: Details of Patients in Non-Fused Type Group

\begin{tabular}{|c|c|c|c|c|c|c|c|c|c|c|}
\hline Pts & $\begin{array}{l}\text { Age } \\
\text { (yrs) }\end{array}$ & Sex & $\begin{array}{l}\text { Symptom duration } \\
\text { (months) }\end{array}$ & $\begin{array}{l}\text { Follow-up } \\
\text { (months) }\end{array}$ & $\begin{array}{l}\text { OLF } \\
\text { level }\end{array}$ & $\begin{array}{l}\text { Pre-Op } \\
\text { mJOA }\end{array}$ & $\begin{array}{c}\text { Post-op } \\
\text { mJOA }\end{array}$ & $\begin{array}{l}\text { Follow-up } \\
\text { mJOA }\end{array}$ & RR (\%) & $\begin{array}{l}\text { Distance of } \\
\text { OLF to the } \\
\text { disc (mm) }\end{array}$ \\
\hline 1 & 49 & $M$ & 4 & 37 & $\mathrm{~T} 11-12$ & 5 & 8 & 9 & $66.7 \%$ & 3.2 \\
\hline 2 & 66 & $\mathrm{~F}$ & 12 & 29 & T9-10 & 6 & 9 & 10 & $80.0 \%$ & 2.2 \\
\hline 3 & 57 & $\mathrm{~F}$ & 36 & 46 & T9-10 & 7 & 9 & 11 & $100.0 \%$ & 2.4 \\
\hline 4 & 53 & $M$ & 5 & 29 & $\mathrm{~T} 11-12$ & 4 & 5 & 9 & $71.4 \%$ & 2.5 \\
\hline 5 & 71 & $\mathrm{~F}$ & 26 & 31 & T3-4 & 5 & 7 & 8 & $50.0 \%$ & 5.3 \\
\hline 6 & 75 & $\mathrm{~F}$ & 36 & 37 & $\mathrm{~T} 11-12$ & 5 & 8 & 9 & $66.7 \%$ & 1.0 \\
\hline 7 & 72 & $M$ & 3 & 34 & T3-4 & 7 & 9 & 10 & $75.0 \%$ & 2.3 \\
\hline 8 & 45 & $\mathrm{~F}$ & 1 & 32 & $\mathrm{~T} 10-11$ & 5 & 8 & 9 & $66.7 \%$ & 1.2 \\
\hline 9 & 61 & $\mathrm{M}$ & 8 & 28 & $\mathrm{~T} 11-12$ & 6 & 8 & 9 & $60.0 \%$ & 2.0 \\
\hline 10 & 43 & $\mathrm{M}$ & 2 & 34 & $\mathrm{~T} 10-11$ & 5 & 8 & 9 & $66.7 \%$ & 0.9 \\
\hline 11 & 44 & $\mathrm{M}$ & 24 & 30 & T9-10 & 4 & 8 & 10 & $85.7 \%$ & 2.4 \\
\hline 12 & 61 & $\mathrm{~F}$ & 2 & 35 & $\mathrm{~T} 10-11$ & 4 & 7 & 8 & $57.1 \%$ & 2.3 \\
\hline 13 & 49 & $\mathrm{~F}$ & 2 & 33 & T3-4 & 4 & 7 & 8 & $57.1 \%$ & 4.6 \\
\hline 14 & 58 & $\mathrm{M}$ & 6 & 43 & $\mathrm{~T} 10-11$ & 5 & 8 & 9 & $66.7 \%$ & 0.2 \\
\hline 15 & 59 & $\mathrm{~F}$ & 3 & 39 & T9-10 & 3 & 6 & 7 & $50.0 \%$ & 3.2 \\
\hline 16 & 59 & $\mathrm{~F}$ & 3 & 41 & $\mathrm{~T} 11-12$ & 6 & 9 & 10 & $80.0 \%$ & 1.7 \\
\hline 17 & 70 & $\mathrm{M}$ & 6 & 26 & T3-4 & 5 & 7 & 8 & $50.0 \%$ & 6.1 \\
\hline 18 & 59 & $\mathrm{~F}$ & 1 & 30 & $\mathrm{~T} 11-12$ & 4 & 7 & 8 & $57.1 \%$ & 2.1 \\
\hline 19 & 49 & $\mathrm{M}$ & 1 & 41 & T2-3 & 4 & 7 & 8 & $57.1 \%$ & 3.4 \\
\hline 20 & 55 & $M$ & 3 & 36 & $\mathrm{~T} 10-11$ & 5 & 8 & 9 & $66.7 \%$ & -0.1 \\
\hline
\end{tabular}

Pts: Patients, Yrs: Years, Pre-Op: Pre-operation, Post-Op: Post-operation, RR: Recovery rate, M: Male, F: Female, mJOA: Modified Japanese Orthopaedic Association score, OLF: Ossification of ligamentum flavum. 
It is based on axial CT scans. In our study, the classification of non-fused and fused types is based on the morphology of OLF as visualized on CT and MRI at the most severe narrowing level, where the spinal cord is deformed by OLF. In the nonfused type of our classification, epidural fat appeared on the MRI between the bilateral non-fused OLF at the most severe narrowing level. Thus, we suggested a procedure similar to the single-door laminoplasty to be undertaken for the fused type and a procedure similar to the French-door for the nonfused type.

The surgical procedures for the decompression of thoracic myelopathy caused by OLF are technically demanding $(12,24)$. The neurological deterioration rate after surgery has been reported to be as high as $8.4 \%$ (10). The most severe narrowing of the spinal canal was found at the middle level of the facet joints $(22,25)$. At this level, the spinal cord was compressed tightly by the OLF. As shown in our study, the apex of the OLF at the most severe narrowing level was located at approximately $2.7 \mathrm{~mm}$ above the disc. This level is the key site for a safe decompression. Any surgical instrument inside the spinal canal at this level may be associated with an increased risk of irreversible spinal cord injury. For a safe neurological decompression, our surgical techniques based on single-door or French-door strategies emphasize the enbloc elevation of the laminae with OLF plaque at the most severe narrowing level.

Several posterior decompression methods for thoracic OLF have been advocated previously. These techniques included open-door laminectomy, en-bloc laminectomy, fenestration, hemilaminectomy, and keyhole foraminotomy $(4,7,8,14,17,21,22)$. Some research groups have suggested variations in the surgical techniques (those mentioned above) depending on the type of $\operatorname{OLF}(2,17)$. Aizawa et al. recommended fenestration or French-door laminectomy for the non-fused type of OLF and en-bloc laminectomy for the fused and tuberous type of OLF (2). According to our surgical strategies, described in the present study, the pedicle is the landmark for decompression. Firstly, two transverse grooves

Table II: Details of Patients in Fused Type Group

\begin{tabular}{|c|c|c|c|c|c|c|c|c|c|c|}
\hline Pts & $\begin{array}{l}\text { Age } \\
\text { (yrs) }\end{array}$ & Sex & $\begin{array}{l}\text { Symptom duration } \\
\text { (months) }\end{array}$ & $\begin{array}{l}\text { Follow-up } \\
\text { (months) }\end{array}$ & $\begin{array}{l}\text { OLF } \\
\text { level }\end{array}$ & $\begin{array}{l}\text { Pre-Op } \\
\text { mJOA }\end{array}$ & $\begin{array}{l}\text { Post-op } \\
\text { mJOA }\end{array}$ & $\begin{array}{c}\text { Follow-up } \\
\text { mJOA }\end{array}$ & RR (\%) & $\begin{array}{l}\text { Distance of } \\
\text { OLF to the } \\
\text { disc (mm) }\end{array}$ \\
\hline 1 & 57 & M & 4 & 25 & T10-11 & 5 & 8 & 9 & $66.7 \%$ & 5.2 \\
\hline 2 & 74 & $M$ & 6 & 28 & T3-4 & 5 & 7 & 9 & $71.4 \%$ & 4.1 \\
\hline 3 & 46 & $F$ & 4 & 37 & T10-11 & 3 & 5 & 8 & $62.5 \%$ & 3.6 \\
\hline 4 & 62 & $\mathrm{~F}$ & 6 & 43 & T10-11 & 5 & 9 & 10 & $83.3 \%$ & 3.2 \\
\hline 5 & 49 & $M$ & 7 & 37 & T10-11 & 5 & 7 & 9 & $66.7 \%$ & 3.8 \\
\hline 6 & 70 & $\mathrm{~F}$ & 24 & 41 & T10-11 & 4 & 7 & 9 & $71.4 \%$ & 7.4 \\
\hline 7 & 57 & $\mathrm{~F}$ & 6 & 35 & T9-10 & 3 & 7 & 8 & $62.5 \%$ & 4.3 \\
\hline 8 & 49 & $\mathrm{~F}$ & 12 & 27 & $\mathrm{~T} 11-12$ & 5 & 8 & 10 & $83.3 \%$ & 3.7 \\
\hline 9 & 68 & $M$ & 2 & 32 & T9-10 & 3 & 6 & 8 & $62.5 \%$ & 5.3 \\
\hline 10 & 69 & M & 15 & 48 & T10-11 & 4 & 6 & 8 & $57.1 \%$ & 2.1 \\
\hline 11 & 54 & $\mathrm{~F}$ & 11 & 26 & T10-11 & 4 & 7 & 9 & $71.4 \%$ & 1.6 \\
\hline 12 & 56 & $\mathrm{~F}$ & 1 & 30 & $\mathrm{~T} 11-12$ & 5 & 8 & 10 & $83.3 \%$ & -0.4 \\
\hline 13 & 55 & $\mathrm{~F}$ & 36 & 29 & $\mathrm{~T} 11-12$ & 6 & 9 & 10 & $80.0 \%$ & 0.5 \\
\hline 14 & 55 & M & 1 & 26 & T10-11 & 4 & 8 & 9 & $71.4 \%$ & 2.7 \\
\hline 15 & 61 & $\mathrm{~F}$ & 1 & 34 & T10-11 & 5 & 8 & 9 & $66.7 \%$ & 2.4 \\
\hline 16 & 51 & $\mathrm{~F}$ & 24 & 28 & $\mathrm{~T} 11-12$ & 3 & 7 & 9 & $75.0 \%$ & 2.1 \\
\hline 17 & 62 & $M$ & 2 & 38 & T10-11 & 4 & 7 & 9 & $71.4 \%$ & 1.3 \\
\hline 18 & 63 & $M$ & 1 & 45 & T10-11 & 5 & 8 & 9 & $66.7 \%$ & 5.8 \\
\hline 19 & 68 & $\mathrm{~F}$ & 3 & 31 & T9-10 & 3 & 6 & 7 & $50.0 \%$ & 3.5 \\
\hline 20 & 56 & $\mathrm{~F}$ & 1 & 25 & T11-12 & 4 & 7 & 8 & $57.1 \%$ & -1.9 \\
\hline
\end{tabular}

Pts: Patients, Yrs: Years, Pre-Op: Pre-operation, Post-Op: Post-operation, RR: Recovery rate, M: Male, F: Female, mJOA: Modified Japanese Orthopaedic Association score, OLF: Ossification of ligamentum flavum. 
with 3-4 $\mathrm{mm}$ width are fashioned by drilling at the pedicle level. Since there is no OLF at the pedicle level, the epidural at this level can be safely exposed. Then, the two longitudinal grooves are drilled along the internal edge of the pedicle, so that the procedures are outside the spinal canal at the most severe narrowing level. For the fused type, the laminae with the OLF are elevated en-bloc from one side, and the other side serves as a hinge. In the non-fused type, there is epidural fat between the middle of the non-fused OLF at the most severe narrowing level as shown on pre-operative MRI; thus, opening the laminae in the midline by drilling is safe. The bilateral hemilaminae with OLF are elevated en-bloc outside for a safe decompression in the non-fused type. In the present study, any spinal cord injury or aggravation of symptoms were not recorded in the patients.

The dura mater typically adheres to the OLF and occasionally ossifies $(11,13,18,23)$. Miyashita et al. suggested leaving a floating fragment adherent to the dura mater in order to avoid CSF fistula in case ossified dura was encountered (11). The study found a spontaneous reduction of the retained ossified fragment during the follow-up. In the current study, we always resected the OLF for a complete decompression during the operation. The adhesion between the OLF and dura was dissected, using a sharp blade, along the edge of the OLF when the laminae with the OLF plaque were elevated en-bloc. In the cases of dural ossification, we resected both the OLF and ossified dura and attempted to maintain the arachnoid in an integral condition. After excision of the OLF with the ossified dura, although a dural defect was noted, a dural tear was absent. If CSF fistula were observed postoperatively, the patient was advised to lie in bed for 2 weeks. However, no CSF-related complications were recorded in our patient cohort.

Several studies have revealed that multilevel laminectomies with the removal of ligaments and facets for the treatment of OLF resulted in a delayed development of kyphotic deformity $(3,5,6,16)$. This increased spinal deformity was speculated to contribute towards potential neurological deterioration. In our techniques, the removal of more than half of the facet joint was essential for establishing the two longitudinal grooves. Therefore, additional pedicle instrumentations and fusion procedures are recommended in our technique. Nonetheless, any distinct instabilities or kyphotic deformities were not observed during the final follow-up.

\section{CONCLUSION}

In thoracic myelopathy caused by OLF, the apex of the OLF at the most severe narrowing level is located $2.7 \mathrm{~mm}$ above the disc level. This level is the key site for surgical decompression. Thus, we emphasize the en-bloc elevation of the laminae with the OLF plaque at this level. Based on our classification of the fused and non-fused types of OLF, different surgical strategies should be adopted. The pedicle is the landmark for a safe neurological decompression in thoracic myelopathy caused by OLF employing our technique.

\section{ACKNOWLEDGMENT}

Shandong Province College Science and Technology Project (J15LL10, ZR2015050013) and Shandong Natural Research Foundation (ZR2016HM31) grants were received supporting this study.

\section{- REFERENCES}

1. Ahn DK, Lee S, Moon SH, Boo KH, Chang BK, Lee Jl: Ossification of the ligamentum flavum. Asian Spine J 8:89-96, 2014

2. Aizawa T, Sato T, Sasaki H, Kusakabe T, Morozumi N, Kokubun S: Thoracic myelopathy caused by ossification of the ligamentum flavum: Clinical features and surgical results in the Japanese population. J Neurosurg Spine 5:514-519, 2006

3. Ando K, Imagama S, Wakao N, Hirano K, Tauchi R, Muramoto A, Kato F, Yukawa Y, Kawakami N, Sato K, Matsubara $Y$, Kanemura $\mathrm{T}$, Matsuyama $\mathrm{Y}$, Ishiguro $\mathrm{N}$ : Examination of the influence of ossification of the anterior longitudinal ligament on symptom progression and surgical outcome of ossification of the thoracic ligamentum flavum: A multicenter study. J Neurosurg Spine 16:147-153, 2012

4. Baba S, Oshima Y, Iwahori T, Takano Y, Inanami H, Koga H: Microendoscopic posterior decompression for the treatment of thoracic myelopathy caused by ossification of the ligamentum flavum: A technical report. Eur Spine J 25:19121919, 2016

5. Chen XQ, Yang HL, Wang GL, Gu Y, Pan WM, Dong RB, Qiu ZJ, Wu JB, Mei X: Surgery for thoracic myelopathy caused by ossification of the ligamentum flavum. J Clin Neurosci 16: 1316-1320, 2009

6. Gao R, Yuan W, Yang L, Shi G, Jia L: Clinical features and surgical outcomes of patients with thoracic myelopathy caused by multilevel ossification of the ligamentum flavum. Spine J 13:1032-1038, 2013

7. Ikuta K, Tarukado K, Senba H, Kitamura T, Komiya N, Fukutoku Y, Shidahara S: Decompression procedure using a microendoscopic technique for thoracic myelopathy caused by ossification of the ligamentum flavum. Minim Invasive Neurosurg 54:271-273, 2011

8. Jia LS, Chen XS, Zhou SY, Shao J, Zhu W: En bloc resection of lamina and ossified ligamentum flavum in the treatment of thoracic ossification of the ligamentum flavum. Neurosurgery 66:1181-1186, 2010

9. Kuh SU, Kim YS, Cho YE, Jin BH, Kim KS, Yoon YS, Chin DK: Contributing factors affecting the prognosis surgical outcome for thoracic OLF. Eur Spine J 15:485-491, 2006

10. Liao CC, Chen TY, Jung SM, Chen LR: Surgical experience with symptomatic thoracic ossification of the ligamentum flavum. J Neurosurg Spine 2: 34-39, 2005

11. Miyashita T, Ataka H, Tanno T: Spontaneous reduction of a floated ossification of the ligamentum flavum after posterior thoracic decompression (floating method); report of a case (abridged translation of a primary publication). Spine J 13: e79, 2013 
12. Mohindra S, Gupta R, Chhabra R, Gupta SK: Compressive myelopathy due to ossified yellow ligament among South Asians: Analysis of surgical outcome. Acta Neurochir (Wien) 153: 581-587, 2011

13. Muthukumar N: Dural ossification in ossification of the ligamentum flavum: A preliminary report. Spine (Phila $\mathrm{Pa}$ 1976) 34:2654-2661, 2009

14. Nie ZH, Liu FJ, Shen Y, Ding WY, Wang LF: Lamina osteotomy and replantation with miniplate fixation for thoracic myelopathy due to ossification of the ligamentum flavum. Orthopedics 36: e353-359, 2013

15. Nishiura I, Isozumi T, Nishihara K, Handa H, Koyama T: Surgical approach to ossification of the thoracic yellow ligament. Surg Neurol 51: 368-372, 1999

16. Sanghvi AV, Chhabra HS, Mascarenhas AA, Mittal VK, Sangondimath GM: Thoracic myelopathy due to ossification of ligamentum flavum: A retrospective analysis of predictors of surgical outcome and factors affecting preoperative neurological status. Eur Spine J 20: 205-215, 2011

17. Sato T, Kokubun S, Ishii Y: Choice of operative method for ossification of ligamentum flavum based on CT findings. Rinsho Seikeigeka 31: 541-545, 1996

18. Sun X, Sun C, Liu X, Liu Z, Qi Q, Guo Z, Leng H, Chen Z: The frequency and treatment of dural tears and cerebrospinal fluid leakage in 266 patients with thoracic myelopathy caused by ossification of the ligamentum flavum. Spine (Phila $\mathrm{Pa} 1976$ ) 37: E702-707, 2012

19. Tanaka Y, Sato Y, Aizawa T: Surgery for ossification of the ligament flavum. Berlin: Springer, 2006: 265-269
20. Trivedi P, Behari S, Paul L, Banerji D, Jain VK, Chhabra DK: Thoracic myelopathy secondary to ossified ligamentum flavum. Acta Neurochir (Wien) 143: 775-782, 2001

21. Wang T, Yin C, Wang D, Li S, Chen X: Surgical technique for decompression of severe thoracic myelopathy due to tuberous ossification of ligamentum flavum. Clin Spine Surg 30: e7-e12, 2017

22. Yang Z, Xue Y, Dai Q, Zhang C, Zhou HF, Pan JF, Sheng D: Upper facet joint en bloc resection for the treatment of thoracic myelopathy caused by ossification of the ligamentum flavum. J Neurosurg Spine 19: 81-89, 2013

23. Yang Z, Xue Y, Zhang C, Dai Q, Zhou H: Surgical treatment of ossification of the ligamentum flavum associated with dural ossification in the thoracic spine. J Clin Neurosci 20: 212-216, 2013

24. Young WF, Baron E: Acute neurologic deterioration after surgical treatment for thoracic spinal stenosis. J Clin Neurosci 8: 129-132, 2001

25. Zhao Y, Xue Y, Shi N, Zong Y, Yang Z, He D, Wang Y, Ding H, Li $Z$, Tang Y: The CT and intraoperative observation of pedicelossification tunnel in 151 cases of thoracic spinal stenosis from ossification of ligamentum flavum. Eur Spine J 23:13251331, 2014

26. Zhong ZM, Wu Q, Meng TT, Zhu YJ, Qu DB, Wang JX, Jiang JM, Lu KW, Zheng S, Zhu SY, Chen JT: Clinical outcomes after decompressive laminectomy for symptomatic ossification of ligamentum flavum at the thoracic spine. J Clin Neurosci 28: $77-81,2016$ 